\title{
Candidate high myopia loci on chromosomes I8p and I $2 q$ do not play a major role in susceptibility to common myopia
} Grace Ibay' ${ }^{1}$, Betty Doan ${ }^{1}$, Lauren Reider ${ }^{2}$, Debra Dana ${ }^{2}$, Melissa Schlifka ${ }^{2}$, Heping $\mathrm{Hu}^{1}$, Taura Holmes ${ }^{1}$, Jennifer O'Neill ${ }^{1}$, Robert Owens ${ }^{3}$, Elise Ciner ${ }^{4}$, Joan E Bailey-Wilson ${ }^{1}$ and Dwight Stambolian*2

\begin{abstract}
Address: ${ }^{1}$ Inherited Disease Research Branch, National Human Genome Research Institute, National Institutes of Health, 333 Cassell Dr., Suite 2000, Baltimore, MD 21224, USA, ²Dept. of Ophthalmology, University of Pennsylvania, 3535 Market St., Suite 701, Philadelphia, PA 19104, USA, ${ }^{3}$ Owens Optometrics, 654 E. Main St., New Holland, PA 17557, USA and ${ }^{4}$ Pennsylvania College of Optometry, 8360 Old York Rd., Elkins Park, PA 19027, USA

Email: Grace Ibay - ibayg@mail.nih.gov; Betty Doan - bdoan@jhsph.edu; Lauren Reider - Ireider@mail.med.upenn.edu; Debra Dana -ddana@mail.med.upenn.edu; Melissa Schlifka - schlifka@mail.med.upenn.edu; Heping Hu - hhu@cceb.upenn.edu; Taura Holmes - tnholmes@mail.nih.gov; Jennifer O'Neill - joneill@jhsph.edu; Robert Owens - stamboli@mail.med.upenn.edu; Elise Ciner - eciner@pco.edu; Joan E Bailey-Wilson - jebw@mail.nih.gov; Dwight Stambolian* - stamboli@mail.med.upenn.edu

* Corresponding author
\end{abstract}

Published: 03 August 2004

BMC Medical Genetics 2004, 5:20 doi:10.1 186/147I-2350-5-20

This article is available from: http://www.biomedcentral.com/I47/-2350/5/20

(c) 2004 lbay et al; licensee BioMed Central Ltd.

This is an open-access article distributed under the terms of the Creative Commons Attribution License (http://creativecommons.org/licenses/by/2.0), which permits unrestricted use, distribution, and reproduction in any medium, provided the original work is properly cited.
Received: 15 March 2004
Accepted: 03 August 2004

\begin{abstract}
Background: To determine whether previously reported loci predisposing to nonsyndromic high myopia show linkage to common myopia in pedigrees from two ethnic groups: Ashkenazi Jewish and Amish. We hypothesized that these high myopia loci might exhibit allelic heterogeneity and be responsible for moderate /mild or common myopia.
\end{abstract}

Methods: Cycloplegic and manifest refraction were performed on 38 Jewish and 40 Amish families. Individuals with at least $-1.00 \mathrm{D}$ in each meridian of both eyes were classified as myopic. Genomic DNA was genotyped with 12 markers on chromosomes $12 \mathrm{q} 21-23$ and 18pII.3. Parametric and nonparametric linkage analyses were conducted to determine whether susceptibility alleles at these loci are important in families with less severe, clinical forms of myopia.

Results: There was no strong evidence of linkage of common myopia to these candidate regions: all two-point and multipoint heterogeneity LOD scores were $<1.0$ and non-parametric linkage $p$ values were $>0.01$. However, one Amish family showed slight evidence of linkage (LOD>I.0) on I2q; another 3 Amish families each gave LOD >1.0 on 18p; and 3 Jewish families each gave LOD $>1.0$ on $12 \mathrm{q}$.

Conclusions: Significant evidence of linkage (LOD> 3) of myopia was not found on chromosome $18 p$ or $12 q$ loci in these families. These results suggest that these loci do not play a major role in the causation of common myopia in our families studied.

\section{Background}

Myopia is one of the leading causes of vision loss around the world[1]. In the United States, myopia affects approximately $25 \%$ of adult Americans[2]. Ethnic diversity 
appears to distinguish different groups with regard to prevalence. Caucasians have a higher prevalence than African Americans[3]. Asian populations have the highest prevalence rates with reports ranging from 50$90 \%[1,4,5]$. Jewish Caucasians, one of the target populations of the present study, have consistently demonstrated a higher myopia prevalence than the general Caucasian population in both U.S. and European population surveys; Orthodox Jewish males in particular show increased susceptibility[6,7].

Despite many decades of research, little is known about the precise molecular defects and abnormal biochemical pathways that result in myopia. Compelling data from familial aggregation and twin studies indicate that susceptibility to myopia is inherited. Several familial aggregation studies have reported a greater prevalence of myopia in children of myopic parents compared to children of nonmyopic parents [8-12]. Several twin studies have demonstrated a very high heritability (estimates ranging from 60 to $90 \%$ ) for myopia [13-15]. Other recent genetic studies of families with -6.00 D or more of myopia (termed high or pathological myopia) have reported significant linkage to regions on chromosome 18p11.31, 12q21-23, 17q2122 and 7q36 [16-19]. The 18p candidate region has been confirmed in an independent study of high myopia [20]. Mutti et al.[21] examined the hypothesis that families with milder, juvenile onset myopia might show linkage to these same candidate regions. They found no evidence to support such a role in this more common form of myopia but their study was not highly powered in the presence of heterogeneity. Evidence also exists that myopia may be under environmental influences. The rapid increase in the prevalence of myopia over the last several decades suggests that environmental factors are important [22,23]. Furthermore, studies have shown a positive correlation of specific environmental factors, such as nearwork, with myopia [24,25]. It has been postulated that myopia develops in a person who engages in significant periods of sustained nearwork as an adaptive response to achieve better focus for near images[26]. Interestingly, Cordain et al.[27] suggest a positive correlation for myopia with increased consumption of carbohydrates, hyperinsulinemia and type II diabetes. Finally, experimental findings from animal studies show that the refractive state of young chicks will adapt to compensate for refractive errors induced by spectacle lenses[28].

The combination of genetic and environmental influences on the development of myopia suggests that myopia is a complex disorder and should not be classified as a simple Mendelian trait. Further evidence is shown by studies that have reported correlation coefficients for myopia between offspring and parents and between pairs of siblings to lie between 0.07-0.36 [29-32]. Due to the possible complex- ity of myopia, population isolates offer many advantages for genome-wide mapping studies[33]. First, they have reduced genetic complexity. Second, the people in most isolates share a common environment and culture. Differences in diet, exercise, sanitary conditions, and exposure to infectious diseases are minimized. A common language and religion usually promote social cohesion. Therefore, some of the environmental noise surrounding complex diseases that are determined by a combination of nature and nurture may be avoided.

To avoid some of the complexity in mapping genes for myopia we have collected refractive measurements and DNA samples from Amish and orthodox Jewish families with myopia. The Old Order Amish are mostly rural farmers and craftsmen. They lead a culturally and technologically distinct lifestyle. They are a genetically well-defined founder population with large families and well-documented genealogies [34,35]. Family history records of the Amish in Lancaster County, Pennsylvania, beginning from 1727 are highly preserved[36]. Other features of this population include a relatively high standard of living, low migratory tendencies, and no practice of birth control, which facilitate the recruitment of large and extended families.

The orthodox Jewish families in this study are all of Ashkenazi descent, a population with known founder effects in other common diseases[37]. This population also has somewhat larger family sizes than average in the US. In this initial report, we describe the design of our study and show that two regions (18p and $12 \mathrm{q}$ ) previously reported to be linked to high myopia cannot explain the familial aggregation in these families with mostly moderate to milder forms of myopia. We had hypothesized that allelic heterogeneity might exist at these candidate loci such that in addition to highly penetrant alleles for extreme high myopia, there might also exist other susceptibility alleles of (possibly) lower penetrance that produce milder phenotypic forms of myopia. However, we found no strong evidence in support of this hypothesis.

\section{Methods \\ Family screening}

The study protocol adhered to the tenet of the Declaration of Helsinki and was approved by the University of Pennsylvania and the National Human Genome Research Institute, National Institutes of Health institutional review boards. Informed consent was obtained from the subjects after explanation of the nature and possible consequences of the study. The collection of orthodox Jewish individuals was begun by a mass mailing of 3900 letters to all the known orthodox Jewish families living in Lakewood, New Jersey. Questionnaires were sent with letters explaining the study. If willing to participate, individuals 
completed and returned questionnaires that included their contact and physician information. Second and third mailings went out to individuals who did not respond either positively or negatively - to the first mailing. The total number of questionnaires returned was 1,310. All Jewish individuals included in the study were of Ashkenazi heritage. Collection of Amish families was done by an advertisement in an Amish newspaper, referrals from local eye doctors in the Lancaster County community and word of mouth. Criteria for entry into the study included the following: 1) Negative history of systemic or ocular disease which may predispose to myopia, 2) negative history of a premature birth, 3) proband must be affected and must have a family history of myopia in either their parents or children, 4) only one parent (as opposed to both parents) of the proband can be myopic. For the Orthodox Jewish population, an individual's myopic status was obtained from the most recent (within 2 years) measurement of refractive error. If not recent, an individual was given a repeat exam by their local eye doctor or one of the study investigators (D.S.). For the Amish subjects, all participants were examined by a study investigator (D.S.) at the Amish Eye Clinic in Strasburg, PA. Amish participants were brought to the study site because they do not have phone access making it difficult to obtain a past history and records. Cycloplegic refractions were done on all individuals less than 40 years of age with one drop each of $1 \%$ cyclogyl, $1 \%$ mydriacyl and $2.5 \%$ phenylephrine. A manifest refraction was performed if an individual was older than 40 years of age. Classification as myopic required at least $-1.00 \mathrm{D}$ in each meridian of both eyes. Individuals were classified as nonmyopes if they were over 21 years of age and did not meet the above criteria for myopia. Other individuals were classified as nonmyopic if they were 5-10 years old and had $\geq+3.00 \mathrm{D}$ in each meridian, $10-18$ years old with $\geq+2.00 \mathrm{D}$ in each meridian or $18-21$ years old with $\geq+0.50 \mathrm{D}$ in each meridian. All other individuals were classified as unknown for the trait.

This ascertainment protocol resulted in the collection of 40 Amish families and 38 orthodox Jewish families. Of the 40 Amish families, phenotype data were available on 340 persons ( 170 individuals were affected and 170 were unaffected) but only 323 DNA samples were available to be genotyped. In the 38 Jewish families, phenotype data were available for 313 persons (177 affected, 122 unaffected and 14 of indeterminate phenotype) and DNA samples were available and genotyped for 290 of these family members.

\section{DNA extraction and genotyping}

Peripheral blood was collected from family members. High molecular weight genomic DNA extraction from the blood samples was performed with a kit (Puregene; Gen- tra Systems, Inc.; Minneapolis, MN, USA). Polymerase chain reactions were performed in a 17.05 ul volume containing 12-320 ng/ul of DNA; $880 \mathrm{uM}$ each of dATP, dCTP, dGTP, and dTTP; $3 \mathrm{mM} \mathrm{MgCl}$; $10 \mathrm{mM}$ Tris/HCl (pH8.3); $50 \mathrm{mM} \mathrm{KCl;} 0.6 \mathrm{uM}$ of each primer; and 7.6 units/ul of Taq polymerase. Standard thermocycling was as follows: $94^{\circ} \mathrm{C}$ for $30 \mathrm{sec}$, $55^{\circ} \mathrm{C}$ for $30 \mathrm{sec}$. and $72^{\circ} \mathrm{C}$ extension time for $30 \mathrm{sec}$. Markers used included D12S85, D12S1706, D12S346，D12S78， D12S79，D12S86, D18S59, D18S481，D18S63，D18S452，D18S53, and D18S474 located in the $18 \mathrm{p}$ and $12 \mathrm{q}$ regions implicated in high myopia $[16,17]$.

\section{Power studies}

A simulation study was conducted on the first 44 Ashkenazi Jewish families collected in this study, using the computer program SIMLINK [38,39], to compare the projected power from alternative parametric trait models (five of these families contributed no information about linkage and so were not genotyped and the sixth family was dropped after genotyping because of sample problems that resulted in inadequate linkage information). It was assumed that the myopia trait is controlled by an autosomal dominant bi-allelic locus and the frequency of the high risk allele was varied in different simulations, using both 0.05 and 0.01 . The actual observed pedigree structures, trait phenotypes and DNA sample availability were used to simulate the trait locus genotypes and linked and unlinked marker loci were also simulated. A highly polymorphic marker locus (9 equally frequent alleles) was assumed. The power available from these families to detect linkage was evaluated using different models for penetrance and sporadic rates. For each of the 12 models tested, simulations were performed assuming that the underlying proportion of families linked to the same marker locus $(\alpha)$ was $25 \%, 50 \%, 75 \%$ and $100 \%$. Furthermore, for each model at each specified level of $\alpha$, simulations were performed for six recombination distances $(\theta)$ between the disease and the marker loci (i.e., $\theta=0.01$, $0.05,0.1,0.2$, and 0.5 ); for three maximum penetrances (0.6, 0.7 and 0.8$)$ for gene carriers; and for two phenocopy rates $(0.08$ and 0.15$)$. LOD scores assuming homogeneity were calculated for each of 100 replicates. The average LOD score over all replicates (ELod) and its standard deviation were calculated for each model simulated. The power of these families to detect a linkage (i.e., to obtain a LOD score $\geq 3.0$ ) was tabulated for the linked marker and the probability of obtaining a LOD score greater than 1.0 when no linkage exists (Type I error) was tabulated for the unlinked marker in all simulations.

\section{Linkage analysis}

The data on 40 Amish and 38 Ashkenazi Jewish families were checked for misspecification of family structures, data entry errors and genotyping errors using the program 
Table I: Different parametric models utilized for the linkage analysis

\begin{tabular}{cccc}
\hline Model & Allele Frequency & Penetrance in DD:Dd susceptibility allele carriers & Penetrance in dd normal homozygotes \\
\hline 1 & 0.0133 & 0.90 & 0.00 \\
2 & 0.0133 & 0.80 & 0.00 \\
3 & 0.0133 & 0.80 & 0.05 \\
4 & 0.0133 & 0.60 & 0.15 \\
5 & 0.05 & 0.90 & 0.00 \\
6 & 0.05 & 0.80 & 0.00 \\
7 & 0.05 & 0.80 & 0.05 \\
8 & 0.05 & 0.60 & 0.15 \\
9 & 0.10 & 0.90 & 0.00 \\
10 & 0.10 & 0.80 & 0.00 \\
11 & 0.10 & 0.80 & 0.05 \\
12 & 0.10 & 0.60 & 0.15 \\
\hline
\end{tabular}

SIBPAIR[40]. This program was also used to estimate allele frequencies at marker loci from the unrelated founder individuals in the families. Parametric two-point linkage analysis was performed with the MLINK program of the FASTLINK package $[41,42]$ and the utility programs MAKEPED, Linkage Control Program, and Linkage Report Program from LINKAGE 5.1 [43-45]. Intermarker distances (Kosambi cM) of the microsatellite markers were obtained from the Marshfield database http:// research.Marshfieldclinic.org/genetics/Map Markers/ mapmaker/MapFormFrames.html: D12S85-42.78D12S1706-0.53-D12S346-7.22-D12S78-13.44-D12S799.23-D12S86; D18S59-6.94-D18S481-1.36-D18S6310.4-D18S452-22.54-D18S53-30.08-D18S474. To carefully explore the possibility of linkage of common myopia to these high myopia candidate regions, we utilized 12 different parametric models (Table 1). Analyses were performed assuming all combinations of three different frequencies for the myopia susceptibility allele $(0.0133,0.5$ and 0.10 ) and four different sets of genotypic penetrances for the gene carriers and non-gene carriers, respectively: 0.90 and $0.0 ; 0.80$ and $0.0 ; 0.80$ and 0.05 ; and 0.60 and 0.15 . Models 1-4 (Table 1 ) assume an allele frequency for the putative myopia susceptibility allele of 0.0133 , which is the same value used by Young et al. in their linkage studies of high myopia $[16,17]$ and close to the value of 0.01 that showed good power in our power simulation (note that a more frequent allele frequency of 0.05 resulted in similar but always lower predicted power in our simulations than the power obtained when an allele frequency value of 0.01 was used; note also that this allele frequency applies only to the linked trait locus, so that if there are multiple loci and environmental factors involved in causing myopia under a heterogeneity model, any single locus might only account for a small proportion of all myopia cases). No sex difference was assumed in any of these models. All persons younger than age 5 were coded as unknown for the trait. This analysis assumed autosomal dominant inheritance of a myopia susceptibility allele. Recombination fractions were assumed to be equal in men and women. The program HOMOG[46] was used to test for evidence of heterogeneity in the presence of linkage in the two-point parametric linkage analyses. The heterogeneity testing was performed separately in the Jewish and Amish families and also in a joint analysis of LOD scores from the two datasets combined. Multipoint parametric and nonparametric linkage analyses were performed with the GENEHUNTER program[47]. Because of program memory constraints, one large Amish pedigree was split into three small ones for the GENEHUNTER analysis. The parametric analyses in GENEHUNTER used the same models described above, while allowing for locus heterogeneity. The nonparametric statistic $\mathrm{NPL}_{\mathrm{all}}$, which estimates the statistical significance of alleles shared IBD between all affected family members, was calculated also, together with an estimated $P$ value for the Amish and Jewish datasets separately. A nonparametric analysis combining the Amish and Jewish families was then performed by calculating the sum of NPL scores for each family (obtained in the separate Amish and Jewish analyses just described) divided by the square root of the total number of families $(N=78)$ [48] to obtain an overall combined NPL score.

\section{Results \\ Power simulation}

As expected, the estimated average maximum LOD score decreases with the distance between the linked marker locus and the trait locus, and with increasing heterogeneity. However, only minimal changes in projected power for our Ashkenazi families were observed as penetrance, phenocopy rate and disease allele were varied. Projected power was always higher when an allele frequency of 0.01 was used for the susceptibility allele at the trait locus than 
Table 2: Power and ELods from 100 replicates of simulated data, dominant susceptibility allele frequency of 0.01

\begin{tabular}{|c|c|c|c|c|c|c|c|c|c|}
\hline \multirow{3}{*}{$\begin{array}{l}\text { PENETRANCE IN } \\
\text { DD:Dd SUSC. } \\
\text { ALLELE CARRIERS }\end{array}$} & \multirow{3}{*}{$\begin{array}{l}\text { PENETRANCE IN } \\
\text { dd NORMAL } \\
\text { HOMOZYGOTE }\end{array}$} & \multicolumn{8}{|c|}{ \% FAMILIES LINKED } \\
\hline & & \multicolumn{2}{|c|}{$100 \%$} & \multicolumn{2}{|c|}{$75 \%$} & \multicolumn{2}{|r|}{$50 \%$} & \multicolumn{2}{|r|}{$25 \%$} \\
\hline & & Powerl & ELod \pm s.d. ${ }^{2}$ & Power' & ELod \pm s.d. ${ }^{2}$ & Powerl & ELod \pm s.d. ${ }^{2}$ & Power' & ELod \pm s.d. ${ }^{2}$ \\
\hline 0.8 & 0.08 & 100 & $14.0 \pm 0.3$ & 99 & $8.9 \pm 0.3$ & 82 & $4.7 \pm 0.2$ & 18 & $1.7 \pm 0.1$ \\
\hline 0.8 & 0.15 & 100 & $14.7 \pm 0.3$ & 100 & $9.1 \pm 0.3$ & 73 & $4.8 \pm 0.2$ & 14 & $1.6 \pm 0.1$ \\
\hline 0.7 & 0.08 & 100 & $14.8 \pm 0.3$ & 99 & $8.5 \pm 0.3$ & 77 & $4.8 \pm 0.2$ & 17 & $1.8 \pm 0.15$ \\
\hline 0.7 & 0.15 & 100 & $15.2 \pm 0.3$ & 99 & $8.8 \pm 0.3$ & 70 & $4.5 \pm 0.2$ & 14 & $1.6 \pm 0.1$ \\
\hline 0.6 & 0.08 & 100 & $15.0 \pm 0.3$ & 98 & $8.6 \pm 0.25$ & 67 & $4.3 \pm 0.2$ & 14 & $1.7 \pm 0.1$ \\
\hline 0.6 & 0.15 & 100 & $14.2 \pm 0.3$ & 100 & $8.4 \pm 0.3$ & 73 & $4.3 \pm 0.2$ & 5 & $1.2 \pm 0.1$ \\
\hline
\end{tabular}

IPower $=100 \times$ Proportion of replicate samples that yielded a homogeneity LOD score $\geq 3.0^{2}$ ELod $=$ average homogeneity LOD score over all replicates \pm its standard deviation

when an allele frequency of 0.05 was used; however, these differences in power were very small. Table 2 shows a representative sample of the predicted power results for detecting linkage to a marker $5 \mathrm{cM}$ from the trait locus (the average maximum distance that a trait locus would be from our genotyped markers if it fell within the confines of either of these two candidate regions on $18 p$ and $12 q$ ) assuming an autosomal dominant susceptibility allele frequency of 0.01 . If all families were linked to one locus, these families were predicted to have $100 \%$ power to detect linkage to a marker $5 \mathrm{cM}$ away from the trait locus with a LOD of 3 or more (the ELods were all $\geq 14$ ). As less families were linked to the marker locus (i.e., as genetic heterogeneity increased) the power decreased but was still good $(\geq 67 \%)$ if $50 \%$ or more of the families were linked. Even when only $25 \%$ of families were linked to the same locus, the expected LOD score was over 1.0 for all models. Of course, these LOD scores were calculated assuming homogeneity, and it is well known that power can be substantially increased when heterogeneity exists if LOD scores are calculated assuming heterogeneity (HLODs) as we have done in this study. So we would expect our actual power to detect linkage to be even higher than our simulations of heterogeneity predict. Observed Type I error rates were compatible with the nominal Type I error levels for all models. Between 0 and $1 \%$ of replicates produced a LOD score $>1$ at any test map distance for unlinked markers.

\section{Linkage}

Parametric and nonparametric LOD scores were calculated for 40 Amish pedigrees and 38 Jewish pedigrees. The six markers on chromosome 12q21-q23 spanned $73 \mathrm{cM}$, and the six markers on chromosome 18p11.2-p11.32 spanned $70 \mathrm{cM}$. Markers D12S1706, D12S346, D18S59, D18S481 and D18S63 were previously reported by Young et al. $[16,17]$ as showing evidence of linkage to autosomal dominant high myopia. Under all 12 parametric models, the evidence in favor of linkage to these candidate regions was minimal and this evidence varied only slightly as the assumptions of the trait model were changed across the models. Therefore, only the results from model 1 are presented here.

\section{Two-point linkage analyses in the Amish and Jewish populations}

Results of two-point parametric linkage analysis of myopia assuming linkage heterogeneity to the chromosome 12 and 18 markers in 40 Amish families are presented in Table 3. Statistically significant or suggestive linkage under locus homogeneity was not observed for either chromosome 12 or chromosome 18 . Only one marker, D18S474 showed a two-point $\mathrm{LOD} \geq 1.0(\mathrm{LOD}=1.39$ at $\theta=0.3$ ). Testing for linkage heterogeneity using HLODs in HOMOG did not significantly improve the evidence for linkage to any of these markers.

The same markers on chromosome 12q21-q23 and chromosome 18p11.2-p11.32 were analyzed using 38 Ashkenazi Jewish families (Table 4). Statistically significant or suggestive linkage was not observed on either chromosome, no homogeneity LOD scores $\geq 1.0$ were observed, and testing for linkage in the presence of heterogeneity (HLODs in HOMOG) did not alter this result.

Heterogeneity testing using HOMOG in the combined Jewish and Amish families also did not yield any significant evidence of linkage in these two regions, with the maximum HLOD's being 0.39 and 0.95 on chromosomes 12 and 18 respectively.

Furthermore, nonparametric two-point NPL scores did not show any significant evidence for linkage in either the Amish or Jewish populations. The observed combined NPL score of 1.37 for D12S1706 approached nominal significance at $p=0.09$ but was not close to the significance level of at least $\mathrm{p}=0.01$ needed to provide confirmation of a prior linkage[49]. 
Table 3: Two-point parametric LOD scores for myopia (Model I) in 40 Amish Families

\begin{tabular}{|c|c|c|c|c|c|c|c|}
\hline \multirow[b]{2}{*}{ MARKER } & \multicolumn{7}{|c|}{ RECOMBINATION FRACTION, $\theta$} \\
\hline & 0.0 & 0.01 & 0.05 & 0.1 & 0.2 & 0.3 & 0.4 \\
\hline DI2S85 & -19.55 & -12.97 & -9.02 & -6.27 & -2.92 & -1.15 & -0.31 \\
\hline DI2SI706 & -39.91 & -29.33 & -17.82 & -10.79 & -3.85 & -1.06 & -0.18 \\
\hline DI2S346 & -36.18 & -24.54 & -13.68 & -7.57 & -1.99 & -0.14 & 0.08 \\
\hline DI2S78 & -40.39 & -28.61 & -17.98 & -11.46 & -4.57 & -1.5 & -0.33 \\
\hline DI2S79 & -49.21 & -32.42 & -19.78 & -12.36 & -4.82 & -1.5 & -0.2 \\
\hline DI2S86 & -40.95 & -32.39 & -20.01 & -12.52 & -5.14 & -1.85 & -0.43 \\
\hline DI8S59 & -26.98 & -20.07 & -11.74 & -6.77 & -2.2 & -0.48 & -0.02 \\
\hline DI8S48I & -29.61 & -19.93 & -11.02 & -5.99 & -1.42 & -0.04 & 0.16 \\
\hline DI8S63 & -32.32 & -23.1 & -12.11 & -5.98 & -0.87 & 0.5 & 0.35 \\
\hline DI8S452 & -38.37 & -27.85 & -16.16 & -9.31 & -2.76 & -0.35 & 0.15 \\
\hline DI8S53 & -35.69 & -25.42 & -15.08 & -9.07 & -3.22 & -0.77 & -0.01 \\
\hline DI8S474 & -26.64 & -14.04 & -5.89 & -2.01 & 0.94 & 1.39 & 0.7 \\
\hline
\end{tabular}

Table 4: Two-point parametric LOD scores for myopia (Model I) in 38 Ashkenazi Jewish families

\begin{tabular}{|c|c|c|c|c|c|c|c|}
\hline \multirow[b]{2}{*}{ MARKER } & \multicolumn{7}{|c|}{ RECOMBINATION FRACTION, $\theta$} \\
\hline & 0 & 0.01 & 0.05 & 0.1 & 0.2 & 0.3 & 0.4 \\
\hline DI2S85 & -7.5 & -6.71 & -4.62 & -2.56 & -0.44 & 0.19 & 0.17 \\
\hline DI2SI706 & -36.21 & -28.66 & -17.67 & -10.77 & -3.85 & -1.04 & -0.15 \\
\hline DI2S346 & -32.76 & -24.46 & -13.34 & -7.11 & -1.68 & -0.04 & 0.11 \\
\hline DI2S78 & -27.99 & -20.59 & -10.1 & -4.65 & -0.46 & 0.43 & 0.24 \\
\hline DI2S79 & -38.53 & -30.26 & -18.47 & $-|1| .2 \mid$ & -4.12 & -1.24 & -0.26 \\
\hline DI2S86 & -39.59 & -31.68 & -19.83 & -12.58 & -5.12 & -1.8 & -0.45 \\
\hline DI8S59 & -35.34 & -27.25 & -16.82 & -10.69 & -4.4 & -1.51 & -0.26 \\
\hline DI8S48I & -32.69 & -24 & -14.58 & -9.19 & -3.73 & -1.26 & -0.24 \\
\hline DI8S63 & -36.39 & -28.55 & -17.92 & -11.36 & -4.65 & -1.63 & -0.35 \\
\hline DI8S452 & -34.97 & -25.21 & -15.47 & -9.72 & -3.78 & -1.22 & -0.23 \\
\hline DI8S53 & -38.03 & -26.36 & -14.65 & -8.62 & -3.15 & -0.94 & -0.14 \\
\hline DI8S474 & -29.88 & -22.79 & $-|4.4|$ & -9.29 & -3.98 & -1.45 & -0.31 \\
\hline
\end{tabular}

\section{Multipoint linkage analyses in the Amish and Jewish populations}

Multipoint parametric linkage analyses assuming homogeneity were consistently negative in both the Amish and Jewish datasets. A maximum multipoint parametric HLOD of 0.92 was observed at D18S474 in the Amish population. However, multipoint parametric HLOD scores were essentially zero for the chromosome 12 region in the Amish and for both the chromosome 12 and 18 regions in the Jewish families.

The multipoint nonparametric analyses did not show statistically significant evidence for linkage of myopia to either candidate region in the Amish (Figures 1 and 2) or the Jewish (Figures 3 and 4) families. Only very mild evidence for linkage of myopia in the Amish was observed between markers D18S59 and D18S481 (NPL= 1.54, $p=$ 0.05) (Figure 2).

\section{Individual families showing linkage}

Only one Amish family (3061) showed marginal evidence for linkage (LOD > 1.0) to the region previously reported on chromosome 12 (D12S1706 and D12S346) for both two-point and multipoint parametric analyses (Table 5). Three Amish families gave LOD $>1.0$ at 2 markers on chromosome 18p. In both two-point and multipoint parametric analyses, family 3064 showed mild evidence of linkage (LOD $=1.30$ ) to marker D18S63, and families 3049 and 3053 showed slight evidence of linkage to marker D18S474 (two-point LOD $=1.14$ and 1.30, respectively). Simulations using SIMLINK (model 1) showed that for these individual families, the maximum two- 


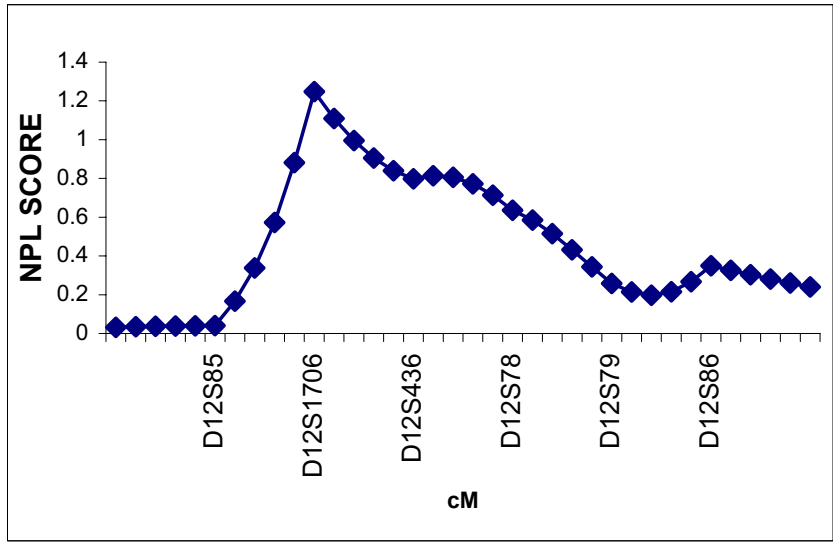

Figure I

Multipoint nonparametric linkage analysis of myopia to chromosome $12 \mathrm{q}$ in 40 Amish families

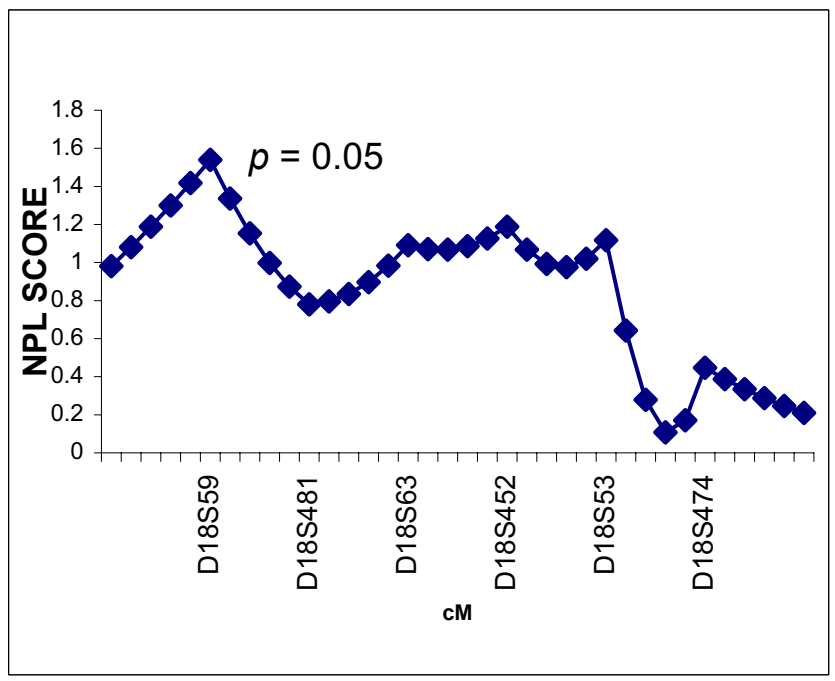

Figure 2

Multipoint nonparametric linkage analysis of myopia to chromosome $18 p$ in 40 Amish families

point LOD score obtained when a linked marker was simulated at a recombination fraction of 0.0 ranged from 0.99 to 1.4 , and the probability of obtaining a LOD over 1.0 for an unlinked marker ranged from $<0.01$ to 0.036 . The nominal significance level corresponding to a LOD score of 1.0 is approximately 0.01 . A total of three Jewish families showed marginal evidence for linkage to chromosome $12 \mathrm{q}$ markers for both two-point and multipoint analyses, with two-point and multipoint parametric LOD $>$ 1.0. Simulations using SIMLINK (model 1) showed that

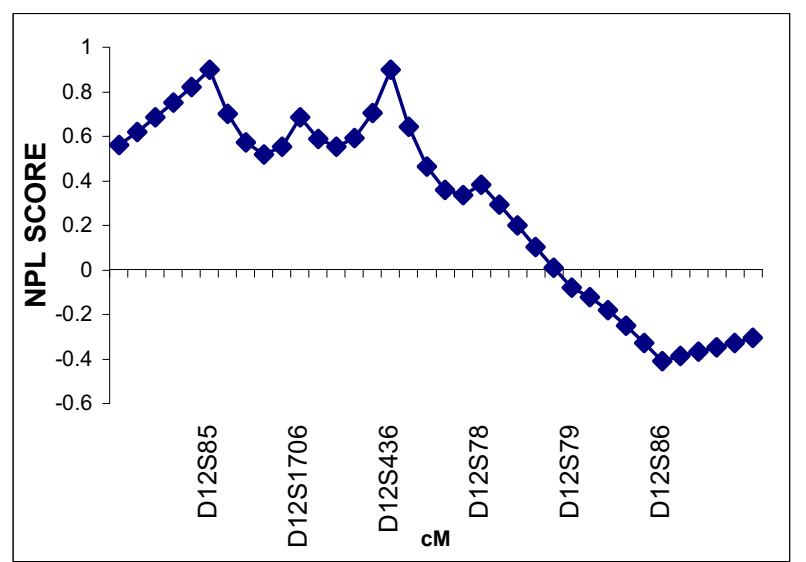

Figure 3

Multipoint nonparametric linkage analysis of myopia to chromosome $12 q$ in 38 Ashkenazi Jewish families

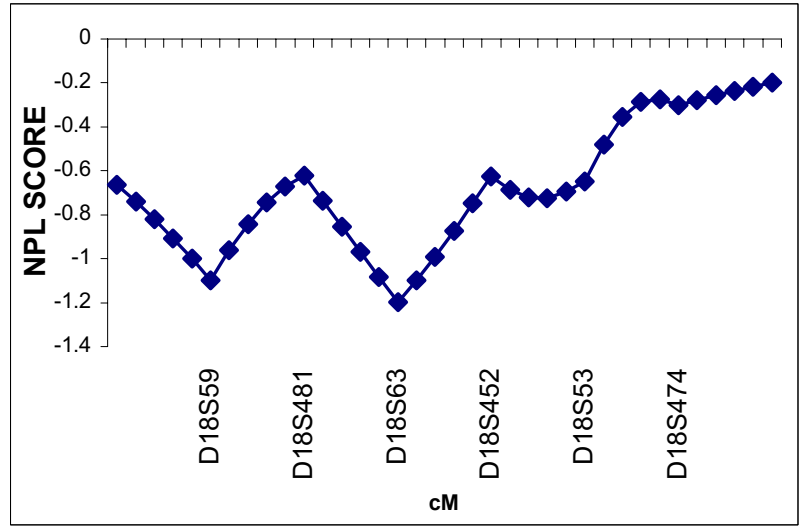

Figure 4

Multipoint nonparametric linkage analysis of myopia to chromosome 18p in 38 Ashkenazi Jewish families

for these individual families the maximum two-point LOD score obtained when a linked marker was simulated at a recombination fraction of 0.0 ranged from 0.93 to 1.06 , and the probability of obtaining a LOD over 1.0 for an unlinked marker ranged from $<0.001$ to 0.05 .

\section{Discussion}

The overall results of these preliminary studies do not indicate any strong evidence for linkage of myopia in these families to the candidate regions on chromosomes 12 or 18 . Although some families show marginal evidence 
Table 5: Families showing slight evidence for linkage of myopia (Model I) to chromosome I2q or I8p

\begin{tabular}{|c|c|c|c|c|c|}
\hline \multicolumn{6}{|c|}{ AMISH FAMILIES } \\
\hline \multirow[t]{2}{*}{ FAMILY ID } & \multicolumn{2}{|c|}{ TWO-POINT LOD } & \multicolumn{3}{|c|}{ MULTIPOINT } \\
\hline & Marker & $Z \max$ & LOD & NPL & $P$ value \\
\hline \multirow[t]{3}{*}{3061} & DI2SI706 & 1.04 & 1.04 & $*$ & $N / A$ \\
\hline & DI2S346 & 1.04 & 1.04 & $*$ & $N / A$ \\
\hline & DI2S78 & 1.04 & 1.04 & $*$ & $N / A$ \\
\hline 3049 & DI8S474 & 1.14 & 1.27 & 2.19 & 0.02 \\
\hline 3053 & DI8S474 & 1.30 & 1.30 & $-*$ & N/A \\
\hline 3064 & DI8S63 & 1.30 & 1.30 & $-*$ & $N / A$ \\
\hline \multicolumn{6}{|c|}{ JEWISH FAMILIES } \\
\hline \multirow[t]{2}{*}{ FAMILY ID } & \multicolumn{2}{|c|}{ TWO-POINT LOD } & \multicolumn{3}{|c|}{ MULTIPOINT } \\
\hline & Marker & $Z \max$ & LOD & NPL & $P$ value \\
\hline \multirow[t]{2}{*}{20} & DI2S79 & 1.12 & 1.12 & 3.45 & 0.02 \\
\hline & DI2S86 & 1.12 & 1.12 & 3.45 & 0.02 \\
\hline \multirow[t]{2}{*}{58} & DI2SI706 & 1.16 & 1.16 & 3.01 & 0.06 \\
\hline & DI2S346 & 1.16 & 1.16 & 3.01 & 0.06 \\
\hline 78 & DI2S85 & 1.07 & 1.07 & 3.38 & 0.01 \\
\hline
\end{tabular}

* Only single affected parent-offspring pairs were genotyped in these families so the NPL analysis was uninformative in these families. However, the parametric LOD score analysis that uses both affected and unaffected family members was informative for linkage.

of linkage to one of these regions, the results could be due to chance. Our negative results for these candidate regions have several possible explanations. First, the diagnostic criteria used in the previous studies $[9,10]$ that implicated these candidate regions were based on limiting the affection status to the sphere component of a plus cylinder refraction. An individual was considered affected with high myopia if the sphere was equal to or greater than $-6 \mathrm{D}$ regardless of the astigmatic error. Our study required an individual to have -1D in each meridian to be considered affected. Therefore, the criterion for being affected was quite different between the two studies. Second, the study population in our study included moderate and low myopes in addition to a small number of high myopes. None of our families showed strong aggregation of high myopia. Therefore, there were no families in our study recruited exclusively for high myopia and no families that would have been highly powerful for the detection of linkage to a high myopia trait. We utilized this study design to search for allelic heterogeneity with regard to the $18 \mathrm{p}$ and $12 \mathrm{q}$ loci thinking that one or both loci may predispose to moderate/mild forms of myopia. Thus, the current linkage analysis was done to test the hypothesis that other alleles at the candidate high myopia loci on chromosomes 18 and 12 might contribute to the etiology of moderate/mild myopia. The mild evidence of linkage in a few families indicates that this hypothesis cannot be fully ruled out for a very small proportion of families with mild forms of myopia. However, there is no strong evidence in favor of this hypothesis and strong negative evidence against linkage in most of the families in this study.

Previous studies attempting to confirm the high myopia loci on chromosomes 18 and 12 have yielded inconsistent results. Naiglin et al.[19]collected 23 French families with high myopia (spherical equivalent $\geq-6 \mathrm{D}$ ) and performed a genome scan with 400 markers. Significant linkage was not found on 18p and 12q. Lam et al.[20] mapped 15 families with high myopia, $\geq-6.0 \mathrm{D}$, using only $18 \mathrm{p}$ markers. Statistically significant (LOD > 3) linkage was not demonstrated although a multipoint LOD over 2.0 was observed, thus giving evidence of confirmation of the $18 \mathrm{p}$ candidate region. Mutti et al.[21] collected 53 families with varying degrees of myopia (affected $\geq-0.75 \mathrm{D}$ in each meridian) and genotyped the family members with $18 \mathrm{p}$ and $12 \mathrm{q}$ loci markers implicated in high myopia. No evidence of linkage to milder forms of myopia was found to the chromosome $18 p$ and $12 q$ loci previously associated with high myopia. Our study, although consistent with the results of Mutti et al.[21] was significantly different in design. First, Mutti et al. used a heterogeneous population that could decrease the chances of obtaining significant linkage for a minor gene effect from $18 \mathrm{p}$ or $12 \mathrm{q}$ if substantial ethnic heterogeneity exists. Both the Amish and Ashkenazi populations used in our study are more homogeneous and each sample was analyzed using marker 
allele frequencies estimated from the sample. Second, their study utilized 221 samples while we genotyped 613 individuals. Our power simulations predicted higher power in the presence of heterogeneity in our Ashkenazi families than was predicted for the Mutti et al. study. Our Amish families were of similar size and structure and so should have similar predicted power as the Ashkenazi families, and our combined analyses of the two data sets should provide much more power than that predicted by the simulations of the Ashkenazi families alone. The combination of the Mutti et al. study with the results presented here strongly suggest that these two candidate regions do not play a large role in the causation of moderate/mild myopia in several populations examined.

These studies suggest that myopia is complex and probably caused by the interaction of multiple genes with the environment. Therefore, to understand myopia it is necessary to apply the equation: Genes + Environment=Outcome. The difficulty here is the uncertainty surrounding both terms in the equation; ideally, one set of genetic factors will interact with one set of environmental influences to produce identical outcomes, but it is unknown whether this is always going to be the case. Therefore, to lessen the problem of multiple gene interaction as well as gene-environment interaction confounding the results, strategies to limit this problem should be utilized in the genetic mapping of myopia. The use of isolated populations is one approach to limiting the heterogeneity across populations and is the approach we are using for a genome wide scan in these families. Furthermore, the definition of myopia needs to be standardized so comparisons across studies can be made accurately. Previous studies have utilized different requirements with regard to affection status making cross comparisons difficult. In conclusion, we find little evidence implicating previously described susceptibility loci for high myopia on chromosomes 12 and 18 as being important in the etiology of common, moderate/mild myopia in our two population samples.

\section{Competing interests}

None declared.

\section{Authors' contributions}

Dwight Stambolian, Lauren Reider, Debra Dana, Robert Owens, and Elise Ciner recruited patients for the study. Melissa Schlifka carried out the genotyping in chromosomes 18 and 12. Dwight Stambolian and Joan E. BaileyWilson performed the study design and wrote part of the manuscript. Joan Bailey-Wilson oversaw all statistical analyses; Grace Ibay performed statistical analyses and wrote part of the manuscript; Taura Holmes, Betty Doan and Jennifer O'Neill assisted with analyses of the data. All authors read and approved of the final manuscript.

\section{Acknowledgment}

This work was supported by the National Eye Institute Grant EYI 2226.

\section{References}

I. Fredrick DR: Myopia. BM/ 2002, 324: | I95-II99.

2. Sperduto RD, Seigel D, Roberts J, Rowland M: Prevalence of myopia in the United States. Arch Ophthalmol 1983, I0 I:405-407.

3. Katz J, Tielsch JM, Sommer A: Prevalence and risk factors for refractive errors in an adult inner city population. Invest Ophthalmol Vis Sci 1997, 38:334-340.

4. Wong TY, Foster PJ, Hee J, Ng TP, Tielsch JM, Chew SJ, Johnson GJ, Seah SK: Prevalence and risk factors for refractive errors in an adult Chinese population in Singapore. Invest Ophthalmol Vis Sci 2000, $41: S 324$

5. Saw SM, Katz J, Schein OD, Chew SJ, Chan TK: Epidemiology of myopia. Epidemiol Rev 1996, 18:175-187.

6. Baldwin W: A review of statistical studies of relations between myopia and ethnic, behaviorial, and physiological characteristics. Am J Opt Physiol Optics I98I, 58:516-527.

7. Zylbermann $R$, Landau $D$, Berson $D$ : The influence of study habits on myopia in Jewish teenagers. J Pediatr Ophthalmol Strab 1993, 30:319-322.

8. Krause UH, Rantakallio PT, Koiranen MJ, Mottonen JK: The development of myopia up to the age of twenty and a comparison of refraction in parents and children. Arctic Med Res 1993, 52:161-165.

9. Hui J, Peck L, Howland HC: Correlations between familial refractive error and children's noncycloplegic refractions. $V$ is Res 1995, 35: I353-1358.

10. Sorsby A, Leary GA, Fraser GR: Family studies on ocular refraction and its components. J Med Genet 1966, 3:269-273.

II. Keller JT: A comparison of the refractive status of myopic children and their parents. Am J Optom Arch Am Acad Optom 1973, 50:206-2II.

12. Yap M, Wu M, Liu ZM, Lee FL, Wang SH: Role of heredity in the genesis of myopia. Ophthalmol Physiol Opt 1993, 13:316-319.

13. Hammond CJ, Snieder H, Gilbert CE, Spector TD: Genes and environment in refractive error: the twin eye study. Invest Ophthalmol Vis Sci 200I, 42: 1232-6.

14. Lyhne N, Sjolie AK, Kyvik KO, Green A: The importance of genes and environment for ocular refraction and its determiners: a population based study among 20-45 year old twins. $\mathrm{Br} J$ Ophthalmol 200I, 85: I470-1476.

15. Teikari JM, Kaprio J, Koskenvuo MK, Vannas A: Heritability estimate for refractive errors: $A$ population based sample of adult twins. Gen Epidemiol 1988, 5:171-I8I.

16. Young TL, Ronan SM, Drahozal LA, Wildenberg SC, Alvear AB, Oetting WS, Atwood LD, Wilkin DJ, King RA: Evidence that a locus for familial high myopia maps to chromosome I8p. Am J Hum Genet 1998, 63:109-119.

17. Young TL, Ronan SM, Alvear AB, Wildenberg SC, Oetting WS, Atwood LD, Wilkin DJ, King RA: A second locus for familial high myopia maps to chromosome I2q. Am J Hum Genet 1998, 63:1419-1424.

18. Paluru P, Ronan SM, Heon E, Devoto M, Wildenberg SC, Scavello G, Holleschau A, Makitie O, Cole WG, King RA, Young TL: New locus for autosomal dominant high myopia maps to the long arm of chromosome 17. Invest Ophthalmol Vis Sci 2003, 44: I830-1836.

19. Naiglin L, Gazagne C, Dallongeville F, Thalamas C, Idder A, Rascol O, Malecaze $F$, Calvas P: A genome wide scan for familial high myopia suggests a novel locus on chromosome 7q36. J Med Genet 2002, 39: I 1 8-24.

20. Lam DSC, Tam POS, Fan DSP, Baum L, Leung Y-F, Pang CP: Familial high myopia linkage to chromosome 18p. Ophthalmologica 2003, $217: 115-118$.

21. Mutti DO, Semina E, Marazita M, Cooper M, Murray JC, Zadnik K: Genetic loci for pathological myopia are not associated with juvenile myopia. Am J Med Genet 2002, I I 2:355-60.

22. Cordain L, Eaton SB, Brand Miller J, Lindeberg S, Jensen C: An evolutionary analysis of the aetiology and pathogenesis of juvenile-onset myopia. Acta Ophthalmol Scand 2002, 80:125-35.

23. Hammond CJ, Snieder H, Gilbert CE, Spector TD: Genes and environment in refractive error: the twin eye study. Invest Ophthalmol Vis Sci 200I, 42:I232-I236. 
24. Kinge B, Midelfart A, Jacobsen G, Rystad J: The influence of nearwork on development of myopia among university students. A three-year longitudinal study among engineering students in Norway. Acta Ophthalmol Scand 2000, 78:26-9.

25. Saw SM, Zhang MZ, Hong RZ, Fu ZF, Pand MH, Tan DT: Near-work activity, night-lights, and myopia in the Singapore-China study. Arch Ophthalmol 2002, I 20:620-627.

26. Goss DA: Nearwork and Myopia. Lancet 2000, 356: | 456-I 457.

27. Cordain L, Eaton SB, Brand Miller J, Lindeberg S, Jensen C: An evolutionary analysis of the aetiology and pathogenesis of juvenile-onset myopia. Acta Ophthalmol Scand 2002, 2: I 25-135.

28. Wildsoet $C$, Wallman J: Choroidal and scleral mechanisms of compensation for spectacle lenses in chicks. Vis Res 1995, 35: I 175-I I94.

29. Sorsby A, Leary GA, Fraser GR: Family studies on ocular refraction and its components. J Med Genet 1966, 3:269-273.

30. Alsbirk PH: Refraction in adult West Greenland Eskimos. Acta Ophthalmol 1979, 57:84-95.

31. Bear JC, Richler A, Burke G: Nearwork and familial resemblances in ocular refraction:a population study in Newfoundland. Clin Genet 1981, 19:462-472.

32. Ashton GC: Segregation analysis of ocular refraction and myopia. Hum Hered 1985, 35:232-239.

33. Arcos-Burgos A, Muenke M: Genetics of population isolates. Clin Genet 2002, 6 I:233-247.

34. McKusick VA: Medical Genetic Studies of the Amish Baltimore, MD, Johns Hopkins University Press; 1978.

35. Cross HE: Population studies and the Old Order Amish. Nature 1976, 262:17-20.

36. Church Directory of the Lancaster County Amish Gordonsville, PA, Peqaea Publishers; 2002

37. Osterer H: A genetic profile of contemporary Jewish populations. Nat Rev Genet 200I, 2:891-898.

38. Ploughman LM, Boehnke M: Estimating the power of a proposed linkage study for a complex genetic trait. Am J Hum Genet 1989, 44:543-55I.

39. Boehnke M: Estimating the power of a proposed linkage study: a practical computer simulation approach. Am J Hum Genet 1986, 39:513-527.

40. Duffy DL: Sibpair: a program for nonparametric linkage/association analysis. Am J Hum Genet suppl 1997, 6 I:A197.

4l. Cottingham RW Jr, Idury RM, Schaffer AA: Faster sequential genetic linkage computations. Am J Hum Genet 1993, 53:252-263.

42. Schaffer AA, Gupta SK, Shriram K, Cottingham RW Jr: Avoiding recomputation in linkage analysis. Hum Hered 1994, 44:225-237.

43. Lathrop GM, Lalouel JM: Easy calculations of lod scores and genetic risks on small computers. Am J Hum Genet 1984, 36:460-465.

44. Lathrop GM, Lalouel JM, Julier C, Ott J: Strategies for multilocus linkage analysis in humans. Proc Natl Acad Sci U S A 1984 8 I:3443-3446.

45. Lathrop GM, Lalouel JM, White RL: Construction of human linkage maps: likelihood calculations for multilocus linkage analysis. Genet Epidemiol 1986, 3:39-52.

46. Ott J: Linkage analysis and family classification under heterogeneity. Ann Hum Genet 1983, 47:3 I I-320.

47. Kruglyak L, Daly MJ, Reeve-Daly MP, Lander ES: Parametric and nonparametric linkage analysis: a unified multipoint approach. Am J Hum Genet 1996, 58: | 347-I363.

48. Xu J: Combined analysis of hereditary prostate cancer linkage to Iq24-25: results from 772 hereditary prostate cancer families from the International Consortium for Prostate Cancer Genetics. Am J Hum Genet 2000, 66:945-957.

49. Lander E, Kruglyak L: Genetic dissection of complex traits: guidelines for interpreting and reporting linkage results. Nat Genet 1995, I I:24 |-247.

\section{Pre-publication history}

The pre-publication history for this paper can be accessed here:

http://www.biomedcentral.com/1471-2350/5/20/prepub
Publish with Bio Med Central and every scientist can read your work free of charge

"BioMed Central will be the most significant development for disseminating the results of biomedical research in our lifetime. "

Sir Paul Nurse, Cancer Research UK

Your research papers will be:

- available free of charge to the entire biomedical community

- peer reviewed and published immediately upon acceptance

- cited in PubMed and archived on PubMed Central

- yours - you keep the copyright
BioMedcentral 